\title{
NEW EDITORIAL STRUCTURE AND POLICIES
}

New editorial policies and a new editorial structure have been developed for the Journal of Paleontology. These are the result of sole responsibility for publication of the Journal now being in the hands of The Paleontological Society, since the membership of the Society voted overwhelmingly (Journal of Paleontology, 1985, No. 3, p. 790) to purchase the Society of Economic Paleontologists and Mineralogists' half share of the Journal.

The new editorial structure consists of a Managing Editor, Associate Managing Editor, and several Technical Editors. This arrangement was designed to disperse the work load. Many of the basic policies of the previous editors of the Journal will continue to be followed, including: content, format, and processing of manuscripts. No change in the overall format of the Journal, in terms of page size or style, is being made at this time. It is likely that such changes will be considered in the future.

We are interested in obtaining manuscripts dealing with all aspects of paleontology, including: taxonomy, stratigraphic paleontology, paleobiogeography, paleoecology, paleobiology, and evolution. Although, in general, manuscripts will be published on a first come, first served basis, the editors reserve the right to give preference to especially significant, or timely, manuscripts. The Journal of Paleontology will continue to be a major outlet for short papers. Large manuscripts may be accommodated in The Paleontological Society's Memoirs, each of which is funded entirely by the author(s). Both the Journal and the Memoirs will continue to be edited by the same staff.

Proper manuscript format, as given on the inside back cover of the Journal, MUST BE FOLLOWED. There will be no exceptions to this policy; manuscripts not in the proper format will immediately be returned to authors. Particular attention should be paid to statements concerning size of half-tone illustrations and line drawings. Clean copy and close proofreading by authors will allow for more rapid processing of manuscripts by the editors.
Processing of manuscripts will be as follows:

(1) Authors are to send their manuscripts to the Managing Editor. He will make an initial review of manuscripts based on format and content. He will then send acceptable manuscripts to reviewers; unacceptable manuscripts will be returned to the author(s) with a statement of the reasons for unacceptability.

(2) Reviewers will return manuscripts to the Managing Editor, who will forward acceptable manuscripts and reviews to one of the Technical Editors. Manuscripts found to be unacceptable at this point will be returned to the author(s) with comments.

(3) When needed, the Technical Editors will return manuscripts to the author(s) for revisions based upon comments by the reviewers or Technical Editors.

(4) Authors will return revised manuscripts to the appropriate Technical Editors for review and mark-up.

(5) Technical Editors will send final manuscripts to the Managing Editor for review. The Managing Editor will send assembled issues to the printer.

(6) By decision of the Council of the Society (Journal of Paleontology, 1985, No. 3, p. 789), "At least one author of a paper [in the Journal] must be a member of The Paleontological Society. Otherwise full page costs must be paid. The editors should use their judgment in setting this rule aside for outstanding papers by authors who can neither join the Society nor pay page charges."

Before a paper by a nonmember is published, page charges must be in hand, or arrangements to waive these must have been made with the Managing Editor.

Requests for page charges, including an invoice, will be made of all authors. Complete, or partial, payment of page charges is an important source of income for the Journal. Our membership has an outstanding record in paying page charges. Continued payment of page charges will allow for more rapid publication, maintain the size of the Journal, and help to reduce the backlog of manuscripts.

(7) Page proofs will be forwarded to the 
author(s) from the printer for checking and any necessary corrections. Authors will send corrected page proofs to the Managing Editor for final proofreading and assembly of issues before forwarding to the publisher.

Charges for excessive corrections on page proof will be sent to the author(s) by the Managing Editor upon receipt of corrected copy. These must be paid promptly.

(8) Longer papers that are deemed acceptable for publication as Memoirs of the $\mathrm{Pa}$ leontological Society will follow the same basic procedures as papers for the Journal. Authors must provide funding for publication in the Memoir series.

(9) Book reviews will be published in the Newsletter. Copy should be sent to the Book Review Editor.

As Editors of the Journal of Paleontology and the Memoirs of the Paleontological So- ciety, we intend to provide a fair and just process of peer review, to process manuscripts as rapidly as is possible, and to maintain the high standards of quality established by previous editors. We ask for your help in returning revisions and proof copy to us as soon as possible.

We applaud the hard work and superior results of the past Editors, of both The Paleontological Society and The Society of Economic Paleontologists and Mineralogists, who have made the Journal of Paleontology an international standard of quality. It is our intention to continue and expand upon this reputation. We ask for your help in support of this goal by providing comments, suggestions, and manuscripts.

The Editors 